\title{
Dental heroes honoured at Smile Awards
}

The individuals and organisations that have done the most to reduce dental decay in fiveyear-olds in Leicester have been honoured in a city council awards scheme. At a ceremony in the city on 5 June 2019, the winners of Leicester's first Smile Awards included a school, a dental practice and a community champion, who have all gone the extra mile to look after local children's teeth.

Members of the public helped the judging panel select the winners by voting online for their favourites, with more than 2,500 votes cast in total. Assistant City Mayor for Public Health Cllr Vi Dempster said: 'Our partners in the health and care sectors are working with us to reduce tooth decay in five-yearolds - and, thanks to their commitment and support, we've seen some very encouraging results over the last five years. Earlier this year, we introduced our new Smile Awards to recognise these individuals and organisations, who constantly go above and beyond to improve oral health in Leicester. I am very grateful to our sponsors for supporting the Smile Awards and I am delighted that our very first Smile Awards have gone to such worthy winners.'

The winners of the 2019 Smile Awards were as follows:

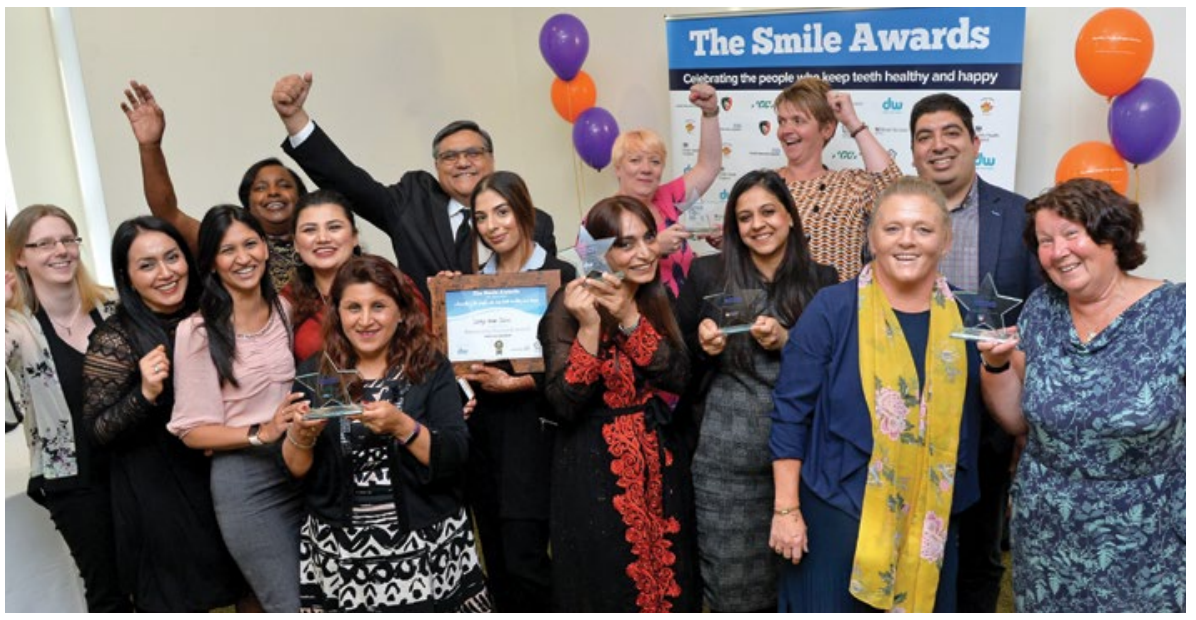

- Dental Practice Award, sponsored by GC UK: Moti Smile Design Centre

- Early Years Award, sponsored by Leicestershire Local Dental Committee: Little Companions

- School Award, sponsored by Henry Schein Dental: Imperial Avenue Infant School

- Community Champion Award, sponsored by DW Design \& Print: Sufiya Ebrahim

- Public Health Nurse (or Practitioner) Award, sponsored by the Leicester Tigers: Healthy Child Programme Practitioner Team (Leicestershire Partnership Trust).
The winners were presented with their Smile Awards by sponsors and members of the judging panel, which comprised Stephen Dixon (Associate Dean and Dental CPD Lead, Health Education England), Jason Wong (Chair of Local Dental Network), Jasmine Murphy (Consultant in Dental Public Health, Public Health England), Jo Atkinson (Consultant in Public Health, Leicester City Council) and Laura Carvell (Programme Officer, Leicester City Council).

Leicester's Smile Awards were delivered in partnership with Health Education England. www.leicester.gov.uk/smileawards.

\section{BOOK REVIEW}

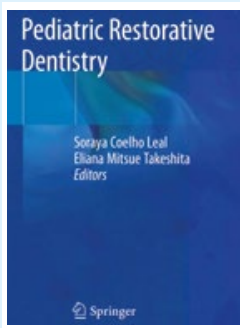

\section{PAEDIATRIC RESTORATIVE DENTISTRY}

Soraya Coelho Leal, Eliana Takeshita

2019

Springer

price f119.99; pp. 228

ISBN: 9783319934259

The 2019 publication of restorative care in paediatric dentistry complements the new series of books published by Springer in the field of paediatric dentistry. The book's initial chapters highlight the philosophy of paediatric dental care, concentrating on the foundations of preventative dentistry, the role of diet and oral health, and note the nuances in the clinical management of the child. The authors cautiously highlight the difficulty in providing a universal book for practitioners. However, this well-structured book, over 16 chapters, guides the reader in the multifaceted approach to restorative care in the child, providing an evidence-based book for practitioners around the world.

Caries in the paediatric population is prevalent worldwide, and caries infiltration and the range of evidence-based clinical management techniques are discussed through the final seven chapters. The clinical illustrations add great value in providing comprehensive, step-by-step techniques to aid the reader in management strategies that may be new to their own clinical setting. Non-restorative approaches to the management of carious lesions such as silver diamine fluoride are discussed, providing indications for its use along with other minimally invasive techniques such as the Hall crown and atraumatic restorative treatment. The chapter on the developmental defects of enamel is comprehensive and includes a cause-effect correlation to aid diagnosis and treatment planning in the management of molar incisor hypomineralisation, amelogenesis imperfecta and fluorosis.

This book has a use for all those providing oral care in paediatric dentistry, especially those within speciality training. Throughout the book, each chapter is well referenced to allow the reader further academic development in evidence-based dentistry. The book provides a practical guide for GDPs and therapists who are seeking to further develop their paediatric restorative skill set and an aid to clinical decision-making; undergraduates will also no doubt find it very helpful.

Carly Dixon 